\title{
pH Sensor Properties of Electrochemically Grown Iridium Oxide
}

\author{
W. OLTHUIS, M. A. M. ROBBEN and P. BERGVELD \\ Department of Electrical Engineering, University of Twente, P.O. Box 217, NL-7500 AE Enschede (The Netherlands) \\ M. BOS and W. E. VAN DER LINDEN \\ Department of Chemical Technology, University of Twente, P.O. Box 217, NL-7500 AE Enschede (The Netherlands)
}

(Received December 19, 1989; in revised form April 24, 1990; accepted May 1, 1990)

\begin{abstract}
The open-circuit potential of an electrochemically grown iridium oxide film is measured and shows a pH sensitivity between -60 and $-80 \mathrm{mV} / \mathrm{pH}$. This sensitivity is found to depend on the state of oxidation of the iridium oxide film; for a higher state of oxidation (or more of the oxide in the high valence state), the sensitivity is also higher. This high sensitivity can be explained on the basis of the extra proton release as a result of the acidic character of the porous hydrous oxyhydroxide, in combination with the redox behaviour.

The response time to a $\mathrm{pH}$ step is measured and is found to depend mainly on the thickness of the oxide; it varies from $40 \mathrm{~ms}$ to $0.35 \mathrm{~s}$ due to the porous nature of the film.

Drift measurements show that an iridium oxide film in reduced state is slowly oxidized by dissolved oxygen, whereas a pre-oxidized film in a $\mathrm{pH}=4.01$ buffer solution in contact with air shows a long-term drift of $<0.3 \mathrm{mV} / \mathrm{h}$.
\end{abstract}

\section{Introduction}

Many research projects have already been carried out on the reversible redox reaction that may occur in iridium oxide. Several papers describe different ways of preparing iridium oxide; electrochemical oxidation of iridium by potential cycling causes the formation of the so-called AIROF (anodic iridium oxide film) [1-11], while $\mathrm{O}_{2}$ plasma reactive sputtering from an Ir target results in a SIROF (sputtered iridium oxide film) [12-17]. Iridium oxide can also be prepared thermally either by decomposition at $450^{\circ} \mathrm{C}$ of a dip-coated $\mathrm{IrCl}_{3} \cdot 3 \mathrm{H}_{2} \mathrm{O}$ film [18] or by thermal oxidation of an iridium-carbon film evaporated on a substrate $[19,20]$.

Disagreement exists over the exact mechanism of the iridium oxide redox system; some authors claim proof for the electron injection-hydroxyl ion ejection mechanism [21], while most others prefer the electron-proton double injection mechanism $[2,12,22,23]$.

The main reason for the interest in iridium oxide stems from the application of this oxide in display devices, because of the electrochromic properties of the redox reaction [1, 24-29]. Some papers mention the application of an iridium oxide electrode because of its catalytic properties for $\mathrm{O}_{2}$ and $\mathrm{Cl}_{2}$ gas evolution [23, 30,31]. The chargestorage property of the oxide attracted the attention of a research group that tries to use an iridium oxide needle in nerve and muscle stimulation [35], while others [32] tried to use an oxidized iridium needle because of its low electrode impedance to measure potentials in biological tissue. The application of iridium oxide as a $\mathrm{pH}$-sensitive electrode resulted in several papers $[5,14,33,34,36]$. The favourable sensor behaviour of the oxide at high temperature and at high pressure in aggressive environments, together with its low impedance look promising [15]. Drift in both offset and sensitivity, however, causes serious problems.

In this paper, the open-circuit potential-pH response of an AIROF wire electrode is measured and discussed as a function of the oxidation state of the iridium oxide. The response time to a pH step of an AIROF evaporated electrode is measured. Also, some measurements have been carried out on the drift behaviour of the wire electrode at constant $\mathrm{pH}$.

From a technological point of view, AIROFs are easier to prepare than SIROFs and, for the latter, an expensive iridium sputter target is required. AIROFs can be grown both on iridium wires with varying diameter and on evaporated Ir films, whereas sputtering is limited to planar structures. Therefore, the research described in this paper is restricted to AIROFs.

\section{Experimental}

Experiments were carried out on an (electrochemically oxidized) Ir wire (Aldrich, $99.9 \%$ ) with

(C) Elsevier Sequoia/Printed in The Netherlands 
a diameter of $0.15 \mathrm{~mm}$ and length of approximately $2 \mathrm{~cm}$, unless otherwise stated. The wire was clamped in a gold connector and rinsed with acetone, ethanol and distilled water and thereafter ultrasonically cleaned in distilled water for $\sim 1 \mathrm{~min}$. Then the wire was dipped in a vessel with $0.5 \mathrm{M} \mathrm{H}_{2} \mathrm{SO}_{4}$ in such a way that only $\sim 15 \mathrm{~mm}$ of the Ir wire was in contact with the acid. Electrochemical oxidation and characterization of the wire was carried out with a PAR 173 potentiostat and a PAR 276 controller, programmed with a personal computer. All potentials were measured and are mentioned relative to a saturated calomel reference electrode (SCE). The growth of the oxide film was accomplished by pulsing (e.g., $[8,9]$ ) of the potential between -0.25 and $1.25 \mathrm{~V}$ at $0.5 \mathrm{~Hz}$. Between 25 and 500 of these potential pulses resulted in a charge exchange (as estimated from the cyclic voltammogram) of 1 to $20 \mathrm{mC} / \mathrm{cm}^{2}$ calculated on the basis of the geometrical area.

The open-circuit potential-pH response was measured in either commercially available Electrofact buffers or in a $\mathrm{NaH}_{2} \mathrm{PO}_{4} / \mathrm{H}_{3} \mathrm{BO}_{3} /$ citric acid buffer solution using an instrumentation amplifier with a very high input resistance (typically $10^{12} \Omega$ ). The $\mathrm{pH}$ was either controlled by the commercial $\mathrm{pH}$ buffers or by the addition of $\mathrm{KOH}$ to the above-mentioned phosphate/borate/citrate buffer solution, in which case it was measured with a glass electrode/pH meter (Radiometer PHM 83). The data of the drift measurements, carried out with the same set up, were sampled and stored in a computer. The temperature of the buffer solutions, stored at room temperature, was $21 \pm 2{ }^{\circ} \mathrm{C}$.

The potential response to a $\mathrm{pH}$ step was measured at an electrochemically oxidized Ir film of $0.1 \mu \mathrm{m}$ thickness evaporated on a $\mathrm{SiO}_{2} / \mathrm{Si}$ chip, on top of $\mathrm{Ti}$ and $\mathrm{Ag}$ adhesion layers. The area of the iridium oxide film that was exposed to the solution was determined by a polyimide layer and measured $1 \mathrm{~mm}^{2}$. The chip was mounted on a small piece of printed circuit board while the edges of the chip and the contact wire were protected from the solution by epoxy. As indicated in Fig. 1, the device was then taped on a reference electrode. The distance between the iridium oxide film and the tip of the reference electrode was $\sim 7 \mathrm{~mm}$.

The continuous flow of liquid between the film and the reference electrode tip assures electrical continuity. During an experiment, the potential of the AIROF was measured by the instrumentation amplifier and sampled by an $\mathrm{A} / \mathrm{D}$ converter (Keithley system 570). The pH step was applied to the iridium oxide using a flow technique by switching a selection valve (Rheodyne type 50) between two vessels, one with a high and one with

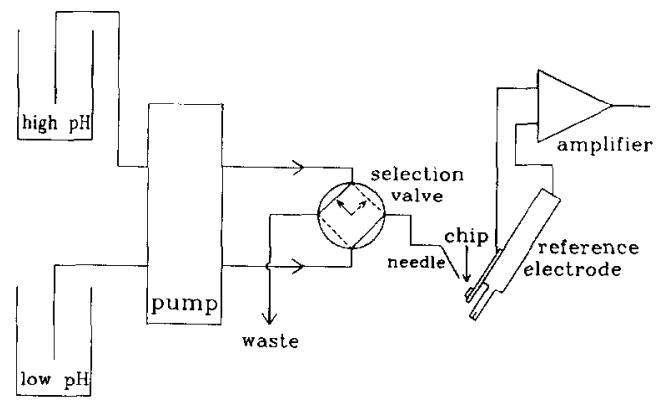

Fig. 1. Measurement set-up for the response time measurements.

a low pH electrolyte. The flow $\left(\sim 5 \mathrm{ml} \mathrm{min}^{-1}\right)$ was controlled by a conventional two-tube peristaltic pump (Gilson Minipuls 2) and squirted from a needle (inner diameter $0.3 \mathrm{~mm}$ ) that was placed approximately $2 \mathrm{~mm}$ from the iridium oxide film.

\section{Results}

\section{Oxide Characterization}

The iridium oxide layer on the wire was characterized by cyclic voltammetry (CV). The very reproducible result is shown in Fig. 2 and is in agreement with $\mathrm{CV}$ curves of AIROF samples reported in other papers (e.g., $[1,2])$.

The geometric area in contact with the solution was $\sim 4.7 \mathrm{~mm}^{2}$. From the $\mathrm{CV}$ in Fig. 2, the amount of charge that is exchanged during the reversible redox reaction of the oxide is estimated at $240 \mu \mathrm{m}$ and so the charge exchange density $\Delta Q$ of this sample is approximately $5.1 \mathrm{mC} / \mathrm{cm}^{2}$.

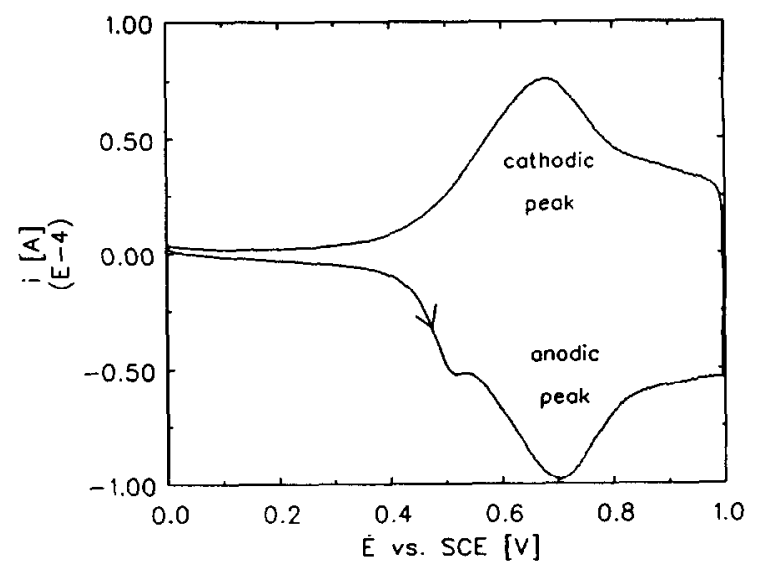

Fig. 2. Typical cyclic voltammogram of an electrochemically grown iridium oxide film in $0.5 \mathrm{M} \mathrm{H}_{2} \mathrm{SO}_{4}$, scan rate $=100 \mathrm{mV} / \mathrm{s}$. 
The evaporated Ir film showed, after electrochemical oxidation, the same features in the CV with a comparable charge exchange density after the same number of growth cycles.

\section{Open-circuit Potential-to-pH Response}

A typical open-circuit potential response of the oxidized iridium wire to the phosphate/borate/citrate buffer solution with added $\mathrm{KOH}$ is shown in Fig. 3. Over a wide pH range, the potential response is measured. A linear line is fitted through the measurement data with a slope of $-69 \mathrm{mV} /$ $\mathrm{pH}$ and a correlation coefficient of 0.9994 .

It was noted during a series of measurements that the $\mathrm{pH}$ sensitivity changed as a function of the oxidation state of the iridium oxide film. In order to investigate this phenomenon, the oxide film was brought into a certain oxidation state (or a certain ratio between possible oxidation states) by applying a constant potential with a potentiostat for $2 \mathrm{~min}$ to the oxidized wire in a $0.5 \mathrm{M} \mathrm{H}_{2} \mathrm{SO}_{4}$ solution. After this treatment the open-circuit potential was measured in three buffers of $\mathrm{pH}=4.01,6.98$ and 9.18. Between each measurement the wire was rinsed with distilled water. The measurements were repeated and showed good reproducibility. Then another constant potential was applied to the same wire in order to change the oxidation state of the oxide, whereafter the potentials were measured again in the three $\mathrm{pH}$ buffers.

These measurements have been carried out for five different states of the iridium oxide and the results are summarized in Table 1.

The state of the oxide is reflected in the opencircuit potential at a certain constant $\mathrm{pH}$; a higher potential corresponds to a higher valence oxide (or to a mixed oxide where the ratio of higher to

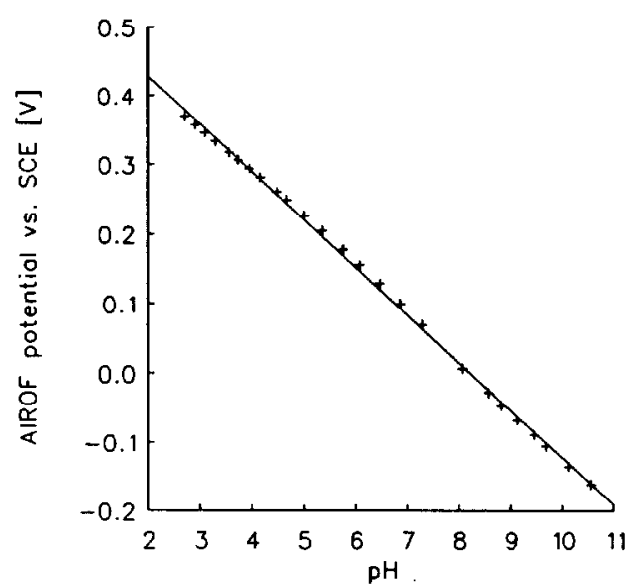

Fig. 3. Typical measurement result of an open-circuit potential-to-pH response.
TABLE 1. pH Sensitivities of an oxidized iridium wire in different oxidation states. The correlation coefficient of a linear fit through the measurement data was $>0.9999$ for each experiment

\begin{tabular}{lll}
\hline $\begin{array}{l}\text { Measurement } \\
\text { number }\end{array}$ & $\begin{array}{l}\mathrm{pH} \text { sensitivity } \\
{[\mathrm{mV} / \mathrm{pH}]}\end{array}$ & $\begin{array}{l}\text { Extrapolated potential } \\
\text { at } \mathrm{pH}=0[\mathrm{mV}]\end{array}$ \\
\hline 1 & 62.0 & 492 \\
2 & 67.1 & 563 \\
3 & 68.7 & 619 \\
4 & 71.3 & 700 \\
5 & 73.6 & 824 \\
\hline
\end{tabular}

lower valence oxide is high) and vice versa. So from Table 1 it is possible to construct a figure where the $\mathrm{pH}$ sensitivity is given as a function of the oxidation state. As a measure for the oxidation state, the (extrapolated) open-circuit potential at $\mathrm{pH}=\mathbf{0}$ was chosen for two reasons: (1) The oxide is commonly characterized by a $\mathrm{CV}$ at $\mathrm{pH}=0$. (2) In the experiment, the oxide is forced into the oxidation state by a constant potential at $\mathrm{pH}=0$. To exclude the possible effect of drift, the potential from the extrapolated $\mathrm{pH}$ measurements as stated in Table 1 is used rather than the applied constant potential itself. The result is presented in Fig. 4.

From this Figure it is clear that the $\mathrm{pH}$ sensitivity increases from $-62 \mathrm{mV} / \mathrm{pH}$ for the reduced state of the oxide to approximately $-74 \mathrm{mV} / \mathrm{pH}$ for the oxidized state.

A comparable result was found for an electrochemically oxidized wire of another diameter $(0.1 \mathrm{~mm}, 99.99 \%)$ in another buffer (the phosphate/borate/citrate buffer solution).

Individual potential-to-pH response measurements showed a minimum sensitivity for the reduced state of approximately $-60 \mathrm{mV} / \mathrm{pH}$ and

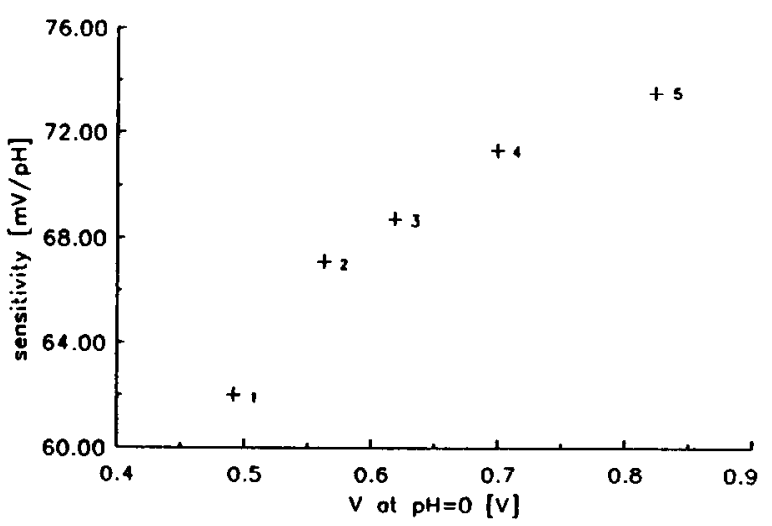

Fig. 4. Measured $\mathrm{pH}$ sensitivities for an iridium oxide film in different oxidation states. Sensitivities numbered 1 to 5 as in Table 1. 
the maximum sensitivity found in the oxidized state was $-79 \mathrm{mV} / \mathrm{pH}$.

\section{Response Time}

In order to test the response time measurement set-up, an ISFET was used as a pH-sensing element. It is known from theory and experimental results [37] that the response of an ISFET to a $\mathrm{pH}$ step is very fast. The value found from theory is typically $2 \mathrm{~ms}$. A pH step from 12 to 2 and vice versa was applied by using $0.1 \mathrm{M} \mathrm{KNO}_{3}$ supporting electrolyte, set to the desired $\mathrm{pH}$ by adding $\mathrm{KOH}$ or $\mathrm{HNO}_{3}$. The result of this experiment is shown in Fig. 5(a) and (b).

Switching of the selection valve causes a very short discontinuity in the flow, which can be observed in the ISFET signal as a sharp spike in Fig. 5(a) and (b). The dead volume of the short tube and needle after the switch causes the delay of $\sim 0.4 \mathrm{~s}$ before the $\mathrm{pH}$ step reaches the gate of the ISFET, as can also be observed in Fig. 5(a) and (b). In this dead volume, some mixing of the
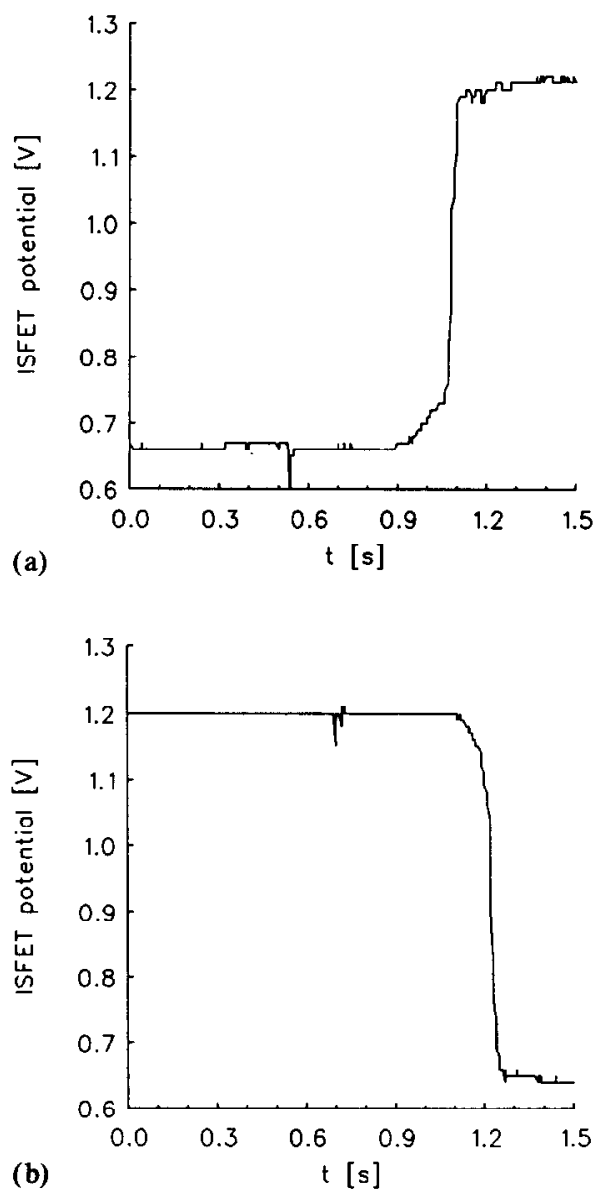

Fig. 5. Measured ISFET response time to a pH step: (a) high-to-low pH step; (b) low-to-high pH step. high- and low-pH electrolyte occurs, causing the initial ( $\sim 0.1 \mathrm{~s}$ ) slow response. The response time, defined as the time needed for $10 \%$ to $90 \%$ transition of the total potential step, measures $\sim 20 \mathrm{~ms}$ for the high-to-low $\mathrm{pH}$ step as well as for the low-to-high pH step. It may be concluded that this time constant is caused by the measurement set-up, because the response time of the ISFET is known to be much smaller than the value found in this experiment.

With this measurement set-up, the response time of a $1 \mathrm{~mm}^{2}$ electrochemically oxidized evaporated Ir film was measured. The results for a high-to-low $\mathrm{pH}$ step and vice versa are shown in Fig. 6(a) and (b).

There is no good explanation for the irregularities in the step response other than that these are probably caused by the measurement set-up with the small diameter injection flow of $0.3 \mathrm{~mm}$ on the $1 \times 1 \mathrm{~mm}$ sensor. The pH-sensitive gate area of an ISFET is much smaller and measures $15 \times 500 \mu \mathrm{m}$, making the latter less dependent on
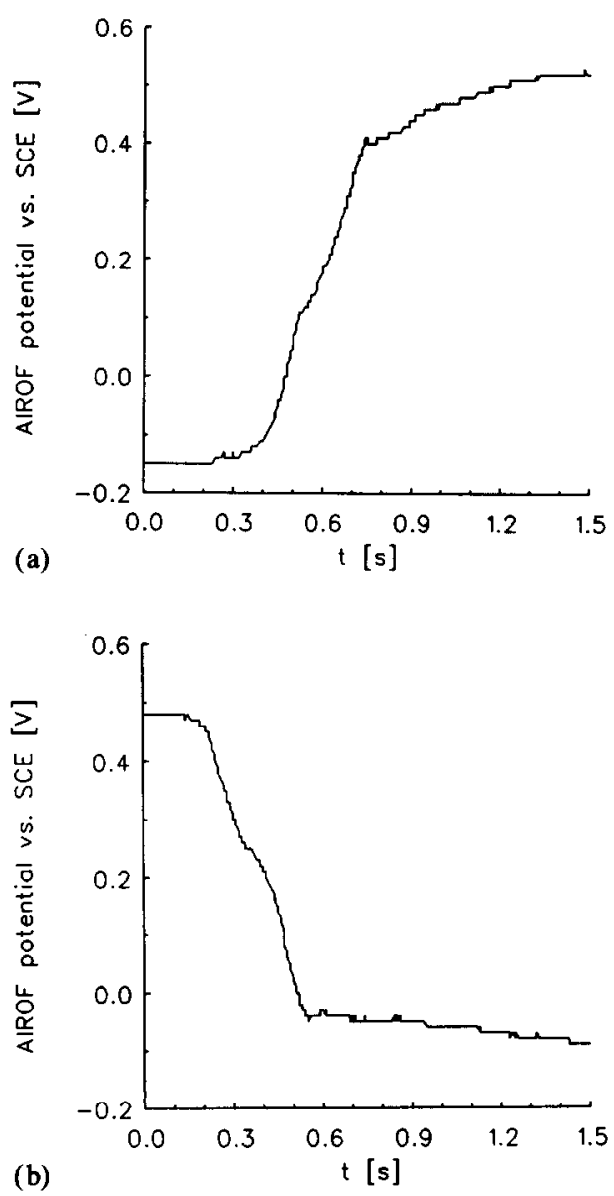

Fig. 6. Measured response of a thick iridium oxide film to a pH step: (a) high-to-low pH step; (b) low-to-high pH step. 
pH differences in the flow caused by convection. The response time that is found, disregarding the slow drift-like behaviour after the step has been applied, is $\sim 0.35 \mathrm{~s}$ for both curves. The curves in Fig. 6(a) and (b) were measured with the oxide in the reduced state. The response time measured with the film in the oxidized state was essentially similar.

The mentioned results were measured for a device with a rather thick oxide film ( 200 growth cycles, $\Delta Q \simeq 7 \mathrm{mC} / \mathrm{cm}^{2}$ ). In order to investigate the influence of the film thickness, the response time experiments were repeated at a thin oxide film ( 25 growth cycles, $\Delta Q \simeq 1 \mathrm{mC} / \mathrm{cm}^{2}$ ). The results are shown in Fig. 7(a) and (b).

The response time found for the high-to-low $\mathrm{pH}$ step is decreased by almost a factor of 10 with respect to that of a thick film and is now $\sim \mathbf{4 0} \mathrm{ms}$. Even after several repetitions of the experiment, the best result obtained from the low-to-high $\mathrm{pH}$ step is still very poor, but the slope of the main
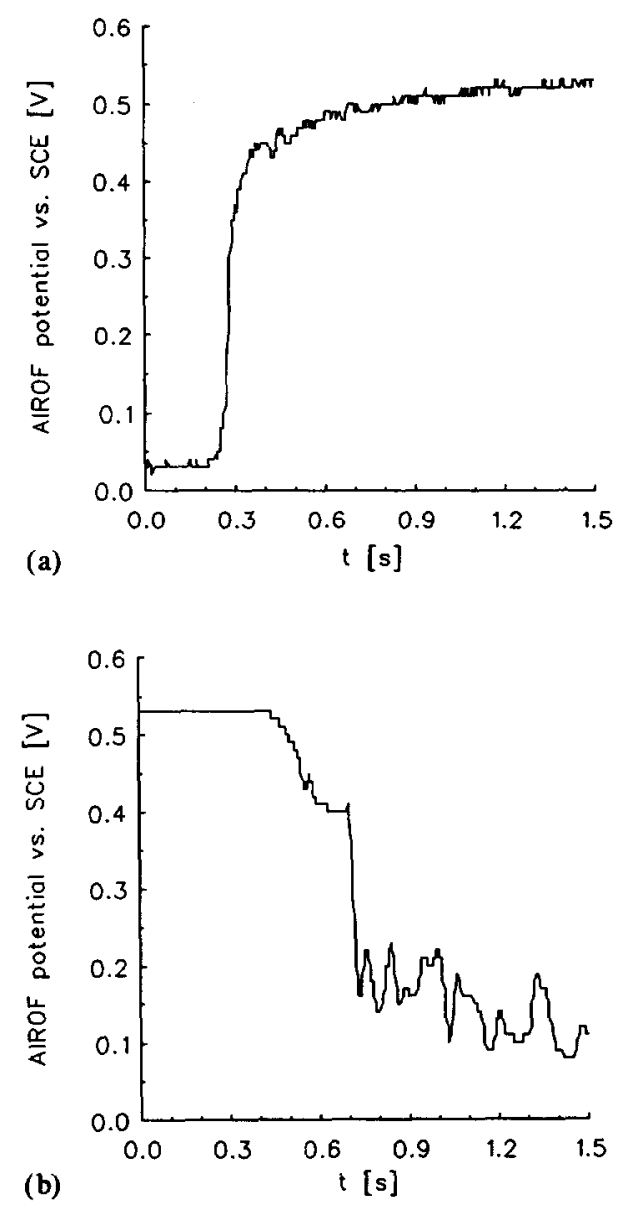

Fig. 7. Measured response of a thin iridium oxide film to a pH step: (a) high-to-low pH step; (b) low-to-high pH step.
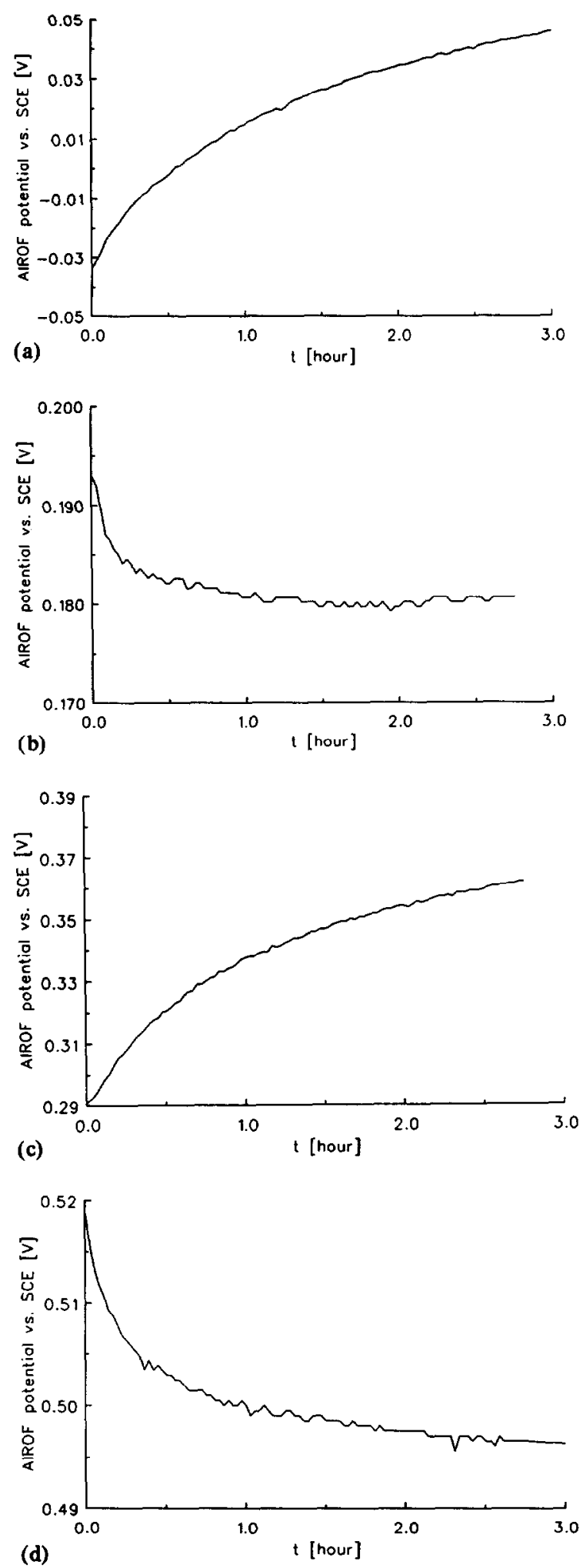

Fig. 8. Measured AIROF drift potentials: (a) $\mathrm{pH}=9.18$, reduced state; (b) $\mathrm{pH}=9.18$, oxidized state; (c) $\mathrm{pH}=4.01$, reduced state; (d) $\mathrm{pH}=4.01$, oxidized state. The end potentials after $17 \mathrm{~h}$ were (a) $0.099 \mathrm{~V}$, (b) $0.179 \mathrm{~V}$, (c) $0.396 \mathrm{~V}$ and (d) $0.483 \mathrm{~V}$. Note the difference in scale. 
part of the step also indicates a decreased response time compared to the thicker oxide film.

\section{Drift Measurements}

Drift measurements have been carried out for two different oxidation states, each at two $\mathrm{pH}$ values. As with the previous measurements, the oxidized iridium wire was brought into an oxidation state by applying a constant potential in a $0.5 \mathrm{M} \mathrm{H}_{2} \mathrm{SO}_{4}$ solution, whereafter the wire was rinsed and placed in one of the two $\mathrm{pH}$ buffers and the measurements were started.

The results of the drift, recorded with the electrode in the solution in contact with air, for the first $3 \mathrm{~h}$ are shown in Fig. 8(a)-(d), together with the end potentials of the same experiments after $17 \mathrm{~h}$. The end potential of the AIROF in oxidized state coincides with the onset of reduction, as is indicated by an arrow in the cyclic voltammograms of Fig. 9(a) and (b), measured in the corresponding $\mathrm{pH}$ buffers. The end potentials of the AIROF which is initially in the reduced state, however, correspond for both $\mathrm{pH}$ values with iridium oxide partly in the oxidized state. To find a possible mechanism for this oxidation, the drift measurements for the AIROF brought into reduced state were repeated, but now with the buffer solution in a nitrogen atmosphere.

The result of the measurements in $\mathrm{pH}=4.01$ is shown in Fig. 10. After a few minutes, the potential reaches a stable value. This value coincides with the onset of oxidation, as can be concluded from Fig. 9(b). After one hour, the nitrogen flow is stopped and the drift measurement is continued in air atmosphere. Then the AIROF apparently oxidizes and shows the same behaviour as in Fig. 8(c). Therefore, under normal conditions, longterm drift behaviour of an AIROF can only sensibly be determined with the oxide in the oxidized state.

The long-term drift (over $15 \mathrm{~h}$ ) in air atmosphere of an AIROF in the oxidized state in a $\mathrm{pH}=4.01$ buffer at $21 \pm 2{ }^{\circ} \mathrm{C}$ is $<0.3 \pm 0.1 \mathrm{mV} / \mathrm{h}$.

\section{Discussion}

It is now widely accepted that the valence of the Ir ion during the reversible redox reaction (the main cathodic and anodic peak of Fig. 2) changes from $\mathrm{Ir}^{3+}$ to $\mathrm{Ir}^{4+}$. It has also been suggested that the electrochemically grown iridium oxide may possibly be a hydrated oxyhydroxide. There is, however, some disagreement concerning the exact stoichiometric composition of this oxyhydroxide.
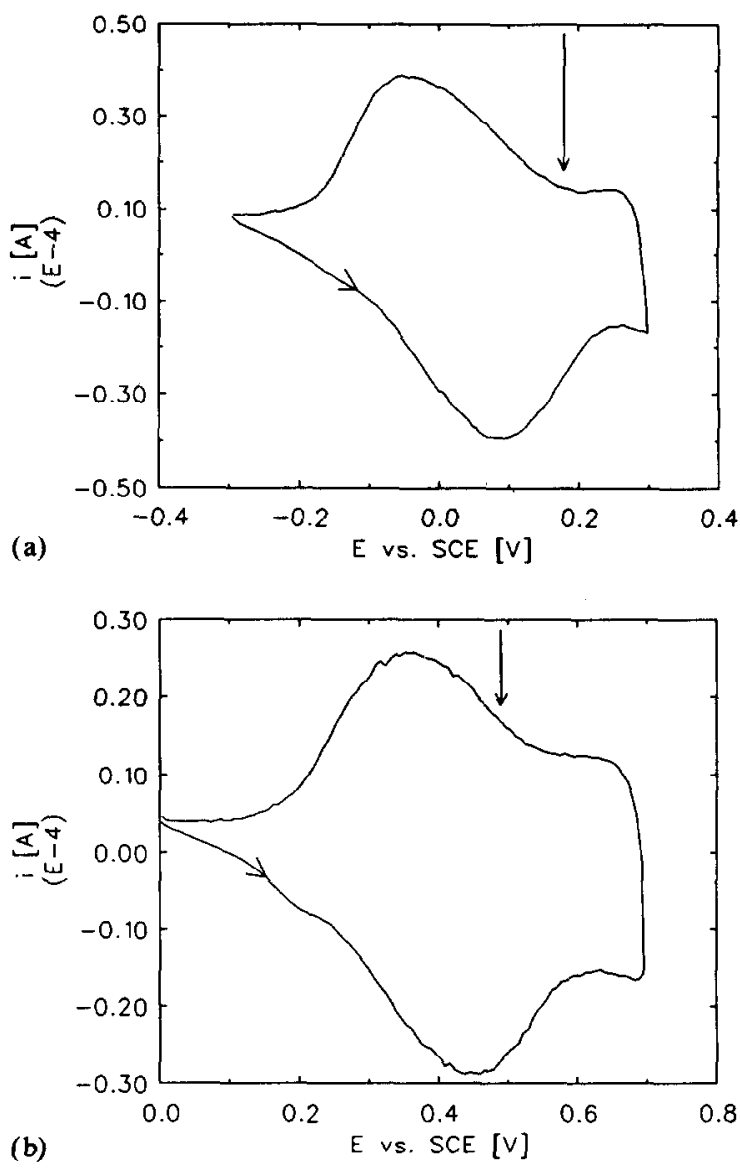

Fig. 9. Cyclic voltammogram of an AIROF measured in stirred solution, scan rate $=25 \mathrm{mV} / \mathrm{s}$ : (a) $\mathrm{pH}=9.18$ buffer; (b) $\mathrm{pH}=4.01$ buffer.

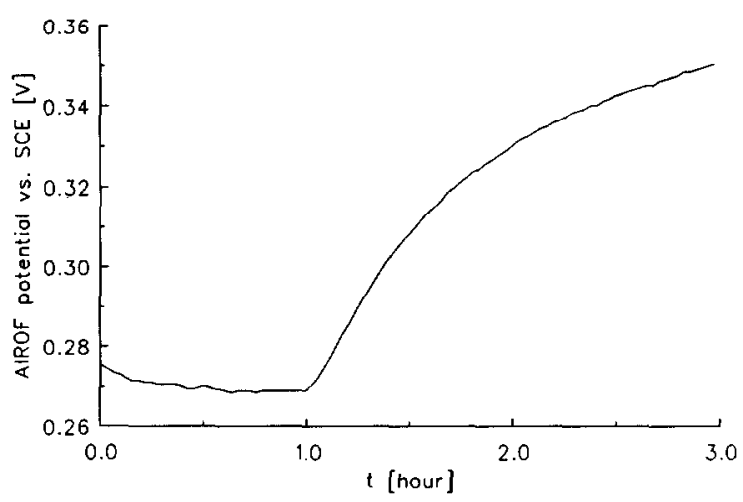

Fig. 10. Measured drift potential of an AIROF in reduced state in $\mathbf{p H}=4.01$ buffer. During the first hour, the solution was bubbled with nitrogen and subsequently left in contact with an air atmosphere.

When only the valences of the involved ions are considered, it is easy to construct Table 2, where all possible $\mathrm{Ir}^{3+}$ and $\mathrm{Ir}^{4+}$ non-hydrated oxyhydroxides and oxides with a maximum of two Ir ions per molecule are listed. 
TABLE 2. Possible forms of iridium oxides and oxyhydroxides

\begin{tabular}{ll}
\hline $\mathrm{Ir}^{3+}$ & $\mathrm{Ir}^{4+}$ \\
\hline $\mathrm{IrO}(\mathrm{OH})$ & $\mathrm{IrO}_{2}$ \\
$\mathrm{Ir}(\mathrm{OH})_{3}$ & $\mathrm{IrO}(\mathrm{OH})_{2}$ \\
$\mathrm{Ir}_{2} \mathrm{O}_{3}$ & $\mathrm{Ir}(\mathrm{OH})_{4}$ \\
$\mathrm{Ir}_{2} \mathrm{O}(\mathrm{OH})_{4}$ & $\mathrm{Ir}_{2} \mathrm{O}_{3}(\mathrm{OH})_{2}$ \\
& $\mathrm{Ir}_{2} \mathrm{O}(\mathrm{OH})_{6}$ \\
\hline
\end{tabular}

Between the reduced and oxidized forms of the oxide or oxyhydroxide, many redox reactions are possible. The exact stoichiometric composition is difficult to determine, especially for the hydrous electrochemically grown film. However, all the possible reactions have in common that the redox reaction mechanism includes either one ejected proton or (more speculatively) one inserted hydroxyl ion per electron during oxidation. This should result in a pH sensitivity (at room temperature) of $-59 \mathrm{mV} / \mathrm{pH}$. This value is found for oxide formed by $\mathrm{O}_{2}$ reactive sputtering $[14,34,36]$. However, the results presented here (and found elsewhere $[5,34]$ ) for an AIROF show a higher open-circuit $\mathrm{pH}$ sensitivity. This high $\mathrm{pH}$ sensitivity $(>|-59| \mathrm{mV} / \mathrm{pH})$ is also found in the shift of the two main peaks of the cyclic voltammogram recorded in electrolytes of different $\mathrm{pH}$. This shift is suggested to be caused by a change in the composition of the oxide during the $\mathrm{CV}$ scan by the redox reaction. This explanation, however, cannot be used to explain the high open-circuit $\mathrm{pH}$ sensitivity, because the composition of the film does not change during these measurements, as the very high input impedance of the instrumentation amplifier and the number of Ir ions present in the film prevent a significant change of the oxidation state. Therefore the explanation of the high open-circuit $\mathrm{pH}$ sensitivity $(-60$ to $-80 \mathrm{mV} / \mathrm{pH}$ ) must be sought through mechanisms other than the redox reaction.

The results of the response time measurements at the thin AIROF show that the kinetics of the $\mathrm{pH}$-sensitive mechanism itself are fast. The overall response time, however, is very much determined by the film thickness. This might indicate that the film is porous: some time is needed for the $\mathrm{pH}$ of the bulk solution to equilibrate with the solution in the pores of the hydrous film.

Hydroxylation of the oxide during growth of the porous, hydrous AIROF causes the presence of many hydroxyl groups. These groups can be considered as amphoteric sites, according to the site-binding theory, which can take up or release a proton, for example

$$
\mathrm{IrO}(\mathrm{OH}) \rightleftharpoons \mathrm{IrOO}^{-}+\mathrm{H}^{+}
$$

$\mathrm{IrO}(\mathrm{OH})+\mathrm{H}^{+} \rightleftharpoons \mathrm{IrO}\left(\mathrm{OH}_{2}\right)^{+}$

These reactions, which do not need electron transfer, may well be the cause of the deviation of the $\mathrm{pH}$ sensitivity from $-59 \mathrm{mV} / \mathrm{pH}$, as has already been pointed out by Burke and Whelan [4]. This can be illustrated by the following example; consider the redox system

$2 \mathrm{Ir}(\mathrm{OH})_{3}+\mathrm{H}_{2} \mathrm{O} \rightleftharpoons \mathrm{Ir}_{2} \mathrm{O}(\mathrm{OH})_{6}+2 \mathrm{H}^{+}+2 \mathrm{e}$

The experiments to determine the open-circuit potential to $\mathrm{pH}$ response as described in the Experimental Section were carried out in a mildly acidic to alkaline solution. Then, the amphoteric character of the hydroxyl groups can be neglected, and the film can be considered only as an acidic oxyhydroxide, each state of the film having its own degree of proton dissociation, for example

$$
\begin{gathered}
\mathrm{Ir}(\mathrm{OH})_{3} \rightarrow \operatorname{Ir}(\mathrm{OH})_{2} \mathrm{O}^{-}+\mathrm{H}^{+} \text {(reduced form) } \\
\mathrm{Ir}_{2} \mathrm{O}(\mathrm{OH})_{6} \rightarrow \mathrm{Ir}_{2} \mathrm{O}(\mathrm{OH})_{3} \mathrm{O}_{3}^{3-}+3 \mathrm{H}^{+} \\
\text {(oxidized form) }
\end{gathered}
$$

Substitution of reactions (4) and (5) into reaction (3) yields

$2 \mathrm{Ir}(\mathrm{OH})_{2} \mathrm{O}^{-}+\mathrm{H}_{2} \mathrm{O} \rightleftharpoons \mathrm{Ir}_{2} \mathrm{O}(\mathrm{OH})_{3} \mathrm{O}_{3}^{3-}+3 \mathrm{H}^{+}+2 \mathrm{e}$

The $\mathrm{pH}$ sensitivity of this system is, according to the Nernst equation, $(-3 / 2)(R T / F)=$ $-88.5 \mathrm{mV} / \mathrm{pH}$ at room temperature. This example indicates the theoretical possibility of a sensitivity $>|-59| \mathrm{mV} / \mathrm{pH}$.

The different measured sensitivities mentioned in Table 1 are believed to be caused by a mixed potential from the two different states of the oxyhydroxide present in the AIROF, the reduced form having a less acidic character than the oxidized form. Depending on the oxidation state of the film, one of the forms is dominant and mainly determines the $\mathrm{pH}$-sensitive behaviour. The oxidation state also determines the composition of the film that causes the electrode potential shift at a fixed $\mathrm{pH}$, as summarized in Table 1 .

As Burke and Whelan [4] have already pointed out, this phenomenon is not a manifestation of super-Nernstian behaviour, as it is often incorrectly called; the $\mathrm{pH}$ sensitivity of $>|-59| \mathrm{mV} / \mathrm{pH}$ can be fully explained by the Nernst equation because Nernstian behaviour only describes the relation between the electrode potential and the activity of the involved species and is no synonym for $-59 \mathrm{mV}$ per decade.

It is interesting to compare the high $\mathrm{pH}$ sensitivity of AIROFs with the sensitivity of $-59 \mathrm{mV} /$ $\mathrm{pH}$ found for SIROFs $[14,34,36]$. The anhydrous, compact, almost non-hydroxylated sput- 
tered iridium oxide does not show the extra effect caused by the dissociation of internal hydroxyl groups as is assumed to be the case for the AIROF.

The result of the drift measurements shows that iridium oxide in a solution in contact with a nitrogen atmosphere is electrochemically stable in any state between totally reduced and totally oxidized. When in the oxidized state, the small initial drift of the oxide potential, shown in Fig. 8(b) and (d), is believed to be caused by the partial discharge of the double-layer capacitance, which continues until the potential corresponding with the onset of Faradaic processes is reached, i.e., the reduction peak in the cyclic voltammogram, where the potential stabilizes in this highimpedance open-circuit drift measurement.

The oxidation of the reduced AIROF in a solution in contact with air can be understood by considering the possible reduction reactions of dissolved $\mathrm{O}_{2}$, leaving out the intermediate species $\mathrm{H}_{2} \mathrm{O}_{2}$ :

$\mathrm{O}_{2}+4 \mathrm{H}^{+}+4 \mathrm{e} \rightleftharpoons 2 \mathrm{H}_{2} \mathrm{O} \quad$ (at low pH)

or

$\mathrm{O}_{2}+2 \mathrm{H}_{2} \mathrm{O}+4 \mathrm{e} \rightleftharpoons 4 \mathrm{OH}^{-} \quad($ at high $\mathrm{pH})$

These reduction reactions can readily consume the electrons supplied by the oxidation reaction (3), resulting in the following net reaction:

$4 \mathrm{Ir}(\mathrm{OH})_{3}+\mathrm{O}_{2} \rightleftharpoons 2 \mathrm{Ir}_{2} \mathrm{O}(\mathrm{OH})_{6}$

The oxidation of the AIROF cannot occur when dissolved oxygen is absent, as can be concluded from reaction (9). This is in agreement with the result of the measurements in a nitrogen atmosphere shown in Fig. 10.

\section{Conclusions}

The measurement results of the response time of the AIROF electrode potential to a $\mathrm{pH}$ step confirm the porous, hydrous nature of this film.

The measured open-circuit potential to $\mathrm{pH}$ response shows a $\mathrm{pH}$ sensitivity of $>|-59| \mathrm{mV} / \mathrm{pH}$. This phenomenon is explained by the acidic character of the oxyhydroxide; the protons released by the internal hydroxyl groups in the film add up to the protons involved in the redox equilibrium, resulting in a sensitivity of $>|-59| \mathrm{mV} / \mathrm{pH}$.

The measured $\mathrm{pH}$ sensitivity of the AIROF in the reduced state is approximately $-60 \mathrm{mV} / \mathrm{pH}$, gradually increasing to $-80 \mathrm{mV} / \mathrm{pH}$ for the AIROF in the fully oxidized state. Therefore, it may be concluded that the degree of dissociation of the hydroxyl groups depends on the oxidation state of the film.

The AIROF in the reduced state slowly oxidizes in a buffer solution in air atmosphere due to the dissolved oxygen, whereas a pre-oxidized AIROF under the same conditions showed a stable potential with a long-term drift of $<0.3 \pm 0.1 \mathrm{mV} / \mathrm{h}$.

Concerning the practical use of an AIROF as a pH sensor, one should bear in mind that the electrode potential is also sensitive to the concentration of oxygen dissolved in the solution. When the oxygen concentration is constant and the AIROF is connected to an instrumentation amplifier in such a way that the electrode remains oxidized, then the use of the AIROF as an absolute $\mathrm{pH}$ sensor with an accuracy of $<0.1 \mathrm{pH}$ between $\mathrm{pH}=2$ and $\mathrm{pH}=11$ for many hours in the solutions mentioned may well be possible, as further research might prove. Its small response time, large range, high sensitivity and ease of use open the possibility of using the sensor successfully as an equivalence point detector in acidbase titrations [38].

\section{Acknowledgements}

The authors thank J. G. Bomer for his expert technical assistance. This investigation is part of the research program of the Foundation for Fundamental Research on Matter (FOM), which is supported by the Netherlands Technology Foundation (STW).

\section{References}

1 S. Gottesfeld, J. D. E. McIntyre, G. Beni and J. L. Shay, Electrochromism in anodic iridium oxide films, Appl. Phys. Lett., 33 (1978) 208-210.

2 S. Gottesfeld and J. D. E. McIntyre, Electrochromism in anodic iridium oxide films, J. Electrochem. Soc., 126(1979) $742-750$.

3 D. N. Buckley, L. D. Burke and J. K. Mulcahy, The oxygen electrode, J. Chem. Soc., Faraday Trans., 72 (1976) $1896-1902$.

4 L. D. Burke and D. P. Whelan, A voltammetric investigation of the charge storage reactions of hydrous iridium oxide layers, J. Electroanal. Chem., 162 (1984) 121-141.

5 L. D. Burke, J. K. Mulcahy and D. P. Whelan, Preparation of an oxidized iridium electrode and the variation of its potential with pH, J. Electroanal. Chem., 163 (1984) 117128.

6 L. D. Burke and R. A. Scannell, An investigation of hydrous oxide growth on iridium in base, $J$. Electroanal. Chem., 175 (1984) 119-141.

7 J. Mozota and B. E. Conway, Surface and bulk processes at oxidized iridium electrode. I. Monolayer stage and transition to reversible multilayer oxide film behaviour, Electrochim. Acta, 28 (1983) 1-8.

8 B. E. Conway and J. Mozota, Surface and bulk processes 
at oxidized iridium electrode. II. Conductivity-switched behaviour of thick oxide films, Electrochim. Acta, 28 (1983) 9-16.

9 P. G. Pickup and V. I. Birss, A model for anodic hydrous oxide growth at iridium, $J$. Electroanal. Chem., 220 (1987) $83-100$.

10 P. G. Pickup and V. I. Birss, The influence of the aqueous growth medium on the growth rate, composition, and structure of hydrous iridium oxide films, $J$. Electrochem. Soc., 135 (1988) 126-133.

11 P. G. Pickup and V. I. Rirss, The kinetics of charging and discharging of iridium oxide films in aqueous and nonaqueous media, J. Electroanal. Chem., 240 (1988) 185-199.

12 S. Hackwood, W. C. Dautremont-Smith, G. Beni, I. M. Schiavone and J. L. Shay, Volume changes induced by the electrochromic process in sputtered iridium oxide films, $J$. Electrochem. Soc., 128 (1981) 1212-1214.

13 L. M. Schiavone, W. C. Dautremont-Smith, G. Beni and J. L. Shay, Electrochromic iridium oxide films prepared by reactive sputtering, Appl. Phys. Lett., 35 (1979) 823-825.

14 T. Katsube, I. Lauks and J. N. Zemel, pH-Sensitive sputtered iridium oxide films, Sensors and Actuators, 2 (1982) $399-410$

15 I. Luaks, M. F. Yuen and T. Dietz, Electrically free-standing $\mathrm{IrO}_{x}$ thin film electrodes for high temperature, corrosive environment $\mathrm{pH}$ sensing, Sensors and Actuators, 4 (1983) 375-379.

16 L. M. Schiavone, W. C. Dautremont-Smith, G. Beni and J. L. Shay, Improved electrochromic behaviour of reactively sputtered iridium oxide films, J. Electrochem. Soc., 128 (1981) $1339-1342$.

17 K. S. Karam and J. L. Shay, Blue sputtered iridium oxide films (blue Sirof's), J. Electrochem. Soc., 130 (1983) 766769.

18 R. M. Ianniello and A. M. Yacynych, Urea sensor based on iridium dioxide electrodes with immobilized urease, Anal. Chim. Acta, 146 (1983) 249-253.

19 Y. Sato, K. Ono, T. Kobayashi, H. Wakabayashi and H. Yamanaka, Electrochromism in iridium oxide films prepared by thermal oxidation of iridium-carbon composite films, J. Electrochem. Soc., 134 (1987) 570-575.

20 Y. Sato, Ellipsometric studies on plasma-oxidation process of iridium-carbon composite films, Jpn. J. Appl. Phys., 25 (1986) 189-193.

21 G. Beni, C. E. Rice and J. L. Shay, Electrochromism of anodic iridium oxide films, J. Electrochem. Soc., 127 (1980) $1342-1348$.

22 J. D. E. McIntyre, S. Basu, W. F. Peck Jr., W. L. Brown and W. M. Augustyniak, Cation insertion reactions of electrochromic tungsten and iridium oxide films, Solid State Ionics, 5 (1981) 359-362.

23 R. Kötz, H. Neff and S. Stucki, Anodic iridium oxide films, XPS-studies of oxidation state changes and $\mathrm{O}_{2}$-evolution, J. Electrochem. Soc., 131 (1984) 72-77.

24 W. C. Dautremont-Smith, Transition metal oxide electrochromic materials and displays: a review. Part 2: oxides with anodic coloration, Displays, (Apr.) (1982) 67-80.

$25 \mathrm{G}$. Beni and J. L. Shay, Electrochromism of heat-treated anodic iridium oxide films in acidic, neutral and alkaline solutions, Appl. Phys. Lett., 33 (1978) 567-568.

26 J. L. Shay, G. Beni and L. M. Schiavone, Electrochromism of anodic iridium oxide films on transparent substrates, Appl. Phys. Lett., 33 (1978) 942-944.

27 W. C. Dautremont-Smith, G. Beni, L. M. Schiavone and J. L. Shay, Solid-state electrochromic cell with anodic iridium oxide film electrodes, Appl. Phys. Lett., 35(1979) 565-567.

$28 \mathrm{G}$. Beni, Short-circuit memory in electrochromic displays, Appl. Phys. Lett., 37 (1980) 106-108.

29 S. Hackwood, G. Beni, W. C. Dautremont-Smith, L. M. Schiavone and J. L. Shay, Temperature dependence of electrochromic processes in iridium oxide displays, Appl. Phys. Lett., 37 (1980) 965-967.

$30 \mathrm{~S}$. Gottesfeld and S. Srinivasan, Electrochemical and optical studies of thick oxide layers on iridium and their electrocatalytic activities for the oxygen evolution reactions, J. Electroanal. Chem., 86 (1978) 89-104.

31 V. Birss, R. Myers, H. Angerstein-Kozlowska and B. E. Conway, Electron microscopy study of formation of thick oxide films on Ir and Ru electrodes, J. Electrochem. Soc., 131 (1984) 1502-1510.

32 F. L. H. Gielen and P. Bergueld, Comparison of electrode impedances of Pt, PtIr (10\% Ir) and Ir-AIROF electrodes used in electrophysiological experiments, Med. Biol. Eng. Comput., 1 (1982) 77-83.

33 N. F. de Rooij and P. Bergveld, The iridium/anodic iridium oxide film (Ir/AIROF) electrode as a pH-sensor, Proc. Int. Conf. on Monitoring of Blood Gases, Blood Ion Concentrations and Respiratory Gas Exchange, Nijmegen, The Netherlands, 1980 , pp. 156-165.

34 M. F. Yuen, I. Lauks and W. C. Dautremont-Smith, pH-Dependent voltammetry of iridium oxide films, Solid State Ionics, 11 (1983) 19-29.

35 S. J. Tanghe, K. Najafi and K. D. Wise, A planar IrO multichannel stimulating electrode for use in neural prostheses, Sensors and Actuators B, 1 (1990) 464-467.

36 M. J. Tarlov, S. Semancik and K. G. Kreider, Mechanistic and response studies of iridium oxide pH sensors, Sensors and Actuators B, I (1990) 293-297.

37 L. J. Bousse, P. Bergveld and W. E. van der Linden, Proc. Scientific Session on Electrochemical Detection in Flow Analysis, Matrafüred, Hungary, Oct. 1982, p. 257.

38 W. Olthuis, B. H. van der Schoot, F. Chavez and P Bergveld, A dipstick sensor for coulometric acid-base titrations, Sensors and Actuators, 17 (1989) 279-283.

\section{Biographies}

Wouter Olthuis was born in Apeldoorn, The Netherlands, on October 23, 1960 . He received the M.S. degree in electrical engineering from the University of Twente in 1986. By his work for the Centre for Micro-Electronics on solid state electret materials for all-silicon microphones, he contacted the Biomedical Engineering Division of the Faculty of Electrical Engineering of the University of Twente, where he started his Ph.D. work on coulometric sensor-actuator systems in 1987.

Marco A. M. Robben was born in Doetinchem, The Netherlands, on December 24, 1966. He started his studies in electrical engineering in 1985 at the University of Twente. He did his practical work at the Rancho Los Amigos Medical Center, Downey, U.S.A. and recently started working for his M.S. degree at the Medisch Spectrum Twente Hospital in Enschede.

Piet Bergueld was born in Oosterwolde, The Netherlands, on January 26,1940 . He received the M.S. degree in electrical engineering from the Univeristy of Eindhoven, The Netherlands, in 1965 and the Ph.D. degree from the University of Twente, The Netherlands, in 1973. The subject of 
his dissertation was the development of ISFETs and related devices. Since 1965 he has been a member of the Biomedical Engineering Division of the Faculty of Electrical Engineering at the University of Twente and was in 1984 appointed as full professor in biosensor technology. He is the chairman of the research unit Sensors and Actuators. His research subjects still concern the further development of ISFETs and biosensors based on ISFET technology.

Ties Bos obtained the M.S. degree in chemical technology at the Technical University of Delft, The Netherlands, in 1965. He got his Ph.D. degree in 1972 from the University of Twente for his work in analytical chemistry. He has been a staff member since 1972 of the Chemical Analysis group of the Faculty of Chemical Technology at the University of Twente.

Willem E. van der Linden studied at the University of Amsterdam (The Netherlands) and received his Ph.D. in analytical chemistry in 1966. He stayed at this university until 1980 when he was appointed as a professor in chemical analysis at the University of Twente, Fnschede. His fields of interest are electroanalytical chemistry and flow analysis, in particular flow-irijection analysis, and their use in process analytical chemistry. $\mathrm{He}$ is one of the editors of Analytica Chimica Acta. 